\title{
Providing hospice in the womb
}

$\mathrm{A}$ my Kuebelbeck was 25 weeks into her pregnancy when she received the terrible news. Her fetus had been diagnosed with an incurable heart defect. If she carried through with her pregnancy, her baby's life would be a brief one.

Kuebelbeck did continue her pregnancy and gave birth to a boy. Her new son, Gabriel, was even sicker than anticipated. He died a few hours after his birth.

"He lived for nine months before he was born," says Kuebelbeck, "and for two and a half peaceful hours afterward."

That was in 1999, a time when perinatal palliative care - support for families expecting babies with life-limiting illnesses - was still very much in the concept stage. There was no formal support program at the hospital where Kuebelbeck, a freelance writer from Saint Paul, Minnesota, received care during her pregnancy with Gabriel. There was, however, one person on staff who helped her family though the entire process.

"One person validated for us that we still had a profound opportunity to parent and love this baby," says Kuebelbeck.

Her experience led to a 2003 memoir, Waiting with Gabriel: A Story of Cherishing a Baby's Brief Life. It also led to the creation of the website perinatalhospice.org, which lists hospitals, mostly in the United States and Canada, that have perinatal hospice programs. When she started the website, in 2006 , there were only 10 programs on that list. Now there are 90 .

"My long-term goal is to take the website down because every hospital has a perinatal hospice program, just as every hospital has an emergency room," says Kuebelbeck.

Perinatal hospice, or "hospice in the womb," begins at the time of prenatal diagnosis, consisting at first of birth planning and preliminary medical decision-making. The goal is to ensure terminally ill babies are comfortable during their short lives, and to provide support to the families of those children

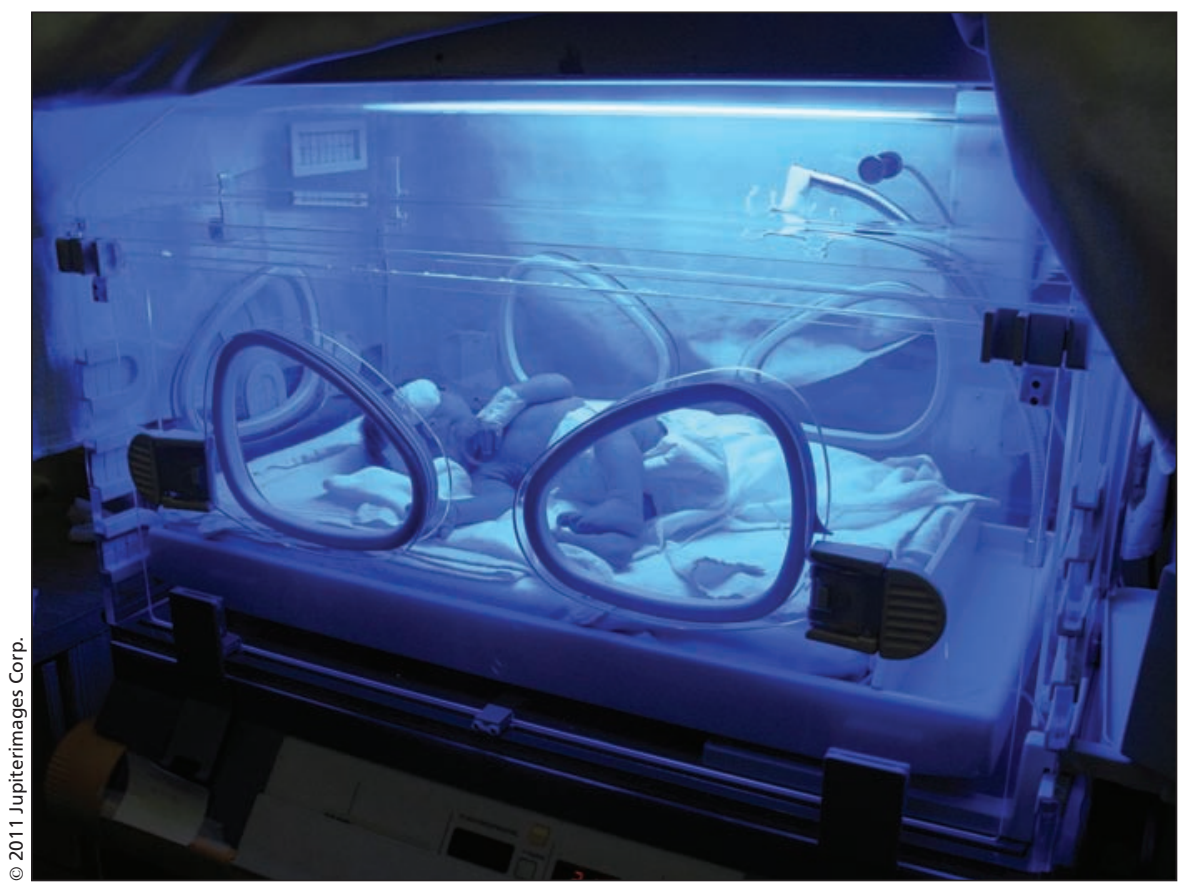

There are now more than 90 perinatal hospice programs in North America.

- before, during and after pregnancy. Perinatal palliative care teams can consist of obstetricians, perinatologists, nurses, neonatologists, social workers, clergy, genetic counsellors, midwives and therapists.

The need for perinatal palliative care arose from the incredible growth of prenatal diagnostic technology. "The testing got ahead of the ability to care for families when the news is bad," says Kuebelbeck.

There hasn't yet been much written on the topic of perinatal hospice, though Kuebelbeck has again contributed to the subject's literature, coauthoring a new book called A Gift of Time: Continuing Your Pregnancy When Your Baby's Life Is Expected to Be Brief.

For the book, she and her coauthor, a developmental psychologist named Deborah Davis, interviewed 120 families - from the United States, Canada, Europe and Australia - who have experienced the loss of a baby with a life-limiting illness.

Some of those families reported positive experiences, having received support from their medical caretakers. Others, however, say they felt abandoned, or, even worse, were made to feel they were making a mistake by continuing their pregnancies, considering the inevitable outcomes.

"Physicians are trained to do something," says Kuebelbeck. "Termination feels like doing something. They may feel that's the best way of helping."

Another common argument in favour of terminating pregnancies in cases of life-limiting illnesses is that it will lessen the negative psychological impact on mothers. Carrying through with the pregnancy and having the baby, according to this theory, only makes the emotional pain worse. Kuebelbeck disagrees.

"The key point is that there is no shortcut for grief. Getting over it sooner does not make it easier," says Kuebelbeck. "If your baby is going to die, your heart is going to break either way. Why not do what you can to fill your heart first?"

If support and care is offered to families in this situation, many will choose it 
over pregnancy termination, says Dr. Byron Calhoun, vice-chair of the department of obstetrics and gynecology at West Virginia University-Charleston. "It takes more effort and more time and requires a different thought process, but if you offer it and provide care, people will choose it," says Calhoun. "People want to be parents."

Calhoun is a pioneer in the field of perinatal palliative care. In fact, he coauthored a 2001 paper that coined the term "perinatal hospice." (Am J Obstet Gynecol 2001;185:525-9). The paper posits termination of pregnancies in cases of lethal fetal conditions has become the "de facto management of choice" primarily because it is favoured by health care providers rather than by pregnant women or the public in general.

If perinatal hospice was an option, it states, it is likely that many people would choose it. Though it is not difficult to set up such a program, it does require heath care professionals to learn about the unique challenges of providing care to families expecting children who won't live long.

"For these families, instead of anticipating the arrival of a new baby, there is contemplation of the impending death of a loved one," the paper states. "Despite the significant increase in awareness and understanding of both prenatal diagnosis and perinatal grief, there remains a great deal of ambiguity, uncertainty, and misunderstanding about how to approach and care for these particular families."

There are certainly no technical barriers to establishing a perinatal hospice, says Dr. Hal Siden, medical director of Canuck Place Children's Hospice, a pediatric palliative care facility in Vancouver, British Columbia. "It's just a matter of sitting down with the people involved and setting up good communication systems," says Siden. "It's not tricky in terms of technology or medications. You just need a good process."

The benefits, however, can be substantial. Families can plan for various scenarios - if the baby lives longer than expected, if the baby lives shorter than expected, if the baby dies in utero, if the baby requires resuscitation measures. Without a plan, parents are often forced to make difficult decisions in the moment, when they are sleep deprived and emotionally spent.

"These children have a very unpre-

dictable course. They could live a few hours or a few weeks," says Siden. "Families are more comfortable if they have a plan."

The results that parents expect from that plan are generally modest and achievable, says Lynn Grandmaison Dumond, an advance practice nurse at Roger's House, a palliative care facility for children in Ottawa, Ontario. "Ultimately, what we found is that these families just want a bit of time with their babies," says Grandmaison Dumond. "They just want to hold their babies, to sing them a lullaby." Roger Collier, CMAJ

CMAJ 2011. DOI:10.1503/cmaj.109-3776

Editor's note: Tenth of a series on end-of-life care

Part I: Preparing for the inevitable (www.cmaj.ca/cgi/doi/10.1503/cmaj.109-3704)

Part II: Advance directives: Obstacles in preparing for the worst (www.cmaj.ca/cgi/doi/10.1503/cmaj.109-3743)

Part III: End-of-life planning framework calls for fewer checklists, more conversation (www.cmaj.ca/cgi/doi/10.1503/cmaj.109-3746)

Part IV: Tools help patients tackle tough choices for end-of-life care (www.cmaj.ca/cgi/doi/10.1503/cmaj.109-3750)

Part V: National home care standards urged (www.cmaj.ca/cgi/doi/10.1503/cmaj.109-3731)

Part VI: Access to palliative care varies widely across Canada (www.cmaj.ca/cgi/doi/10.1503/cmaj.109-3763)

Part VII: Framework urges physicians to proceed with caution on palliative sedation (www.cmaj.ca/cgi/doi/10.1503/cmaj.109-3766)

Part VIII: Pocket-sized help for people with dementia (www.cmaj.ca/cgi/doi/10.1503/cmaj.109-3705)

Part IX: Grief therapy for those left behind

(www.cmaj.ca/cgi/doi/10.1503/cmaj.109-3793) 